\title{
Nüks Rektum Kanserinde İntraoperatif Radyoterapi
}

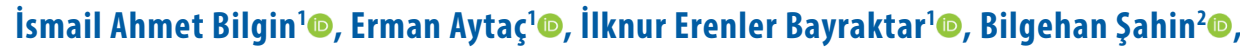

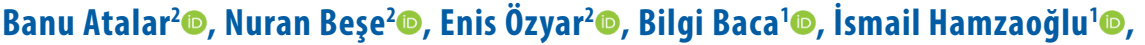 \\ Tayfun Karahasanoğlu ${ }^{1} \odot$
}

${ }^{1}$ Acıbadem Üniversitesi, Genel Cerrahi Anabilim Dalı, İstanbul, Türkiye ${ }^{2}$ Acıbadem Üniversitesi, Radyasyon Onkolojisi Anabilim Dalı, İstanbul, Türkiye

İsmail Ahmet Bilgin, Uzm. Dr. Erman Aytaç, Doç. Dr İlknur Erenler Bayraktar, Doç. Dr Bilgehan Şahin, Uzm. Dr. Banu Atalar, Prof. Dr Nuran Beşe, Prof. Dr Enis Özyar, Prof. Dr Bilgi Baca, Prof. Dr İsmail Hamzaoğlu, Prof. Dr Tayfun Karahasanoğlu, Prof. Dr

Iletişim:

Doç. Dr. Erman Aytaç Acıbadem Üniversitesi, Genel Cerrahi Anabilim Dalı, Istanbul, Türkiye

Tel: +902123044964

E-Posta: eaytactr@yahoo.com

Gönderilme Tarihi : 14 Ağustos 2017

Revizyon Tarihi : 27 Aralık 2017

Kabul Tarihi $\quad$ : 28 Aralık 2017
ÖZET

Giriş: Lokal ileri ve nüks rektum kanserinde multimodal tedavi seçeneklerden biri olan intraoperatif radyoterapi (IORT), lokal kontrolü sağlamak için tercih edilebilir. Bu çalışmada nüks rektum kanseri nedeniyle radikal cerrahi ve intraoperatif radyoterapi uyguladığımız hastalar üzerindeki deneyimimizi sunmayı amaçladık.

Metod: Acıbadem Mehmet Ali Aydınlar Üniversitesi Tıp Fakültesi, Maslak Hastanesi'nde Kasım 2012 ve Aralık 2016 tarihleri arasında nüks rektum kanseri nedeniyle radikal cerrahi ve IORT uygulanan hastaların klinik özellikleri ve ameliyat sonrası takipleri değerlendirildi.

Bulgular: Çalışmamıza nüks rektum kanseri olan 8 hasta (4 kadın) dahil edildi. Tüm hastalarda nüks adenokarsinom mevcuttu. Hastaların ortanca yaş değeri 54.5 (33-67) ve vücut kitle indeksi $24.3(19.6-32.5) \mathrm{kg} / \mathrm{m}^{2}$ idi. Rektum kanseri için yapılan ilk ameliyatların tümü sfinkter koruyucu rezeksiyondu. Nüks tümör nedeniyle 4 hastaya aşağı anterior rezeksiyon, 2 hastaya abdominoperineal rezeksiyon, 2 hastaya da pelvisten kitle çıkarıması işlemi uygulandı. 5 hastaya R0, 2 hastaya $R 1$ ve 1 hastaya R2 rezeksiyon yapıldı. Ameliyat sonrası erken dönem takiplerinde 2 hastada cerrahi yara enfeksiyonu gelişti. Ortanca hastanede kalıs süresi 8 (4-10) gündü. Ortanca 35.5 (7-52) aylık takip süresince 4 hasta hastalıksız takip edilmektedir. íki hastada pelvik nüks gelişti. İki hasta eksitus oldu.

Sonuç: Nüks rektum kanserinde intraoperatif radyoterapi, toksisite riskini azaltarak yüksek doz radyoterapi uygulayabilmemize olanak sağlayan ve bu yolla cerrahinin lokal kontrol üzerindeki etkinliğini artıran bir yöntemdir.

Anahtar sözcükler: Nüks rektum kanseri, intraoperatif radyoterapi, multimodal tedavi

\section{INTRAOPERATIVE RADIATION THERAPY FOR RECURRENT RECTAL CANCER}

\section{ABSTRACT}

Introduction: As one of the multimodal treatment options available in locally advanced or recurrent rectal cancer, intraoperative radiotherapy (IORT) may be a preferred option to achieve local control. In this study, we aim to report on our experience with those recurrent rectal cancer cases which were treated with radical surgery and intraoperative radiotherapy.

Methods: Cases treated with radical surgery and IORT for recurrent rectal cancer between November 2012 and December 2016 at Acibadem Mehmet Ali Aydinlar University Medical Faculty Hospital, Maslak, Istanbul, were included in this study.

Results: 8 patients ( 4 male, 4 female ) with recurrent rectal cancer were included in this study. All the patients had recurrent adenocarcinoma. The median age was 54.5 (range 33-67) and median BMI was 34.3 (range 19.6-32.5) $\mathrm{kg} / \mathrm{m}^{2}$. In all cases, the previous surgery undertaken was sphincter-preserving resection. For recurrent tumors, low anterior resection was performed on 4 patients, abdominoperineal resection was performed on 2 patients and pelvic exenteration was performed on 2 patients. $\mathrm{R} 0$ resection was observed in 5, $\mathrm{R} 1$ in 2, and $\mathrm{R} 2$ in 1 patient. At short-term follow-up, infection had developed at the operative site in 2 patients. The median hospital stay was 8 (4-10) days. During the median follow-up period of 36 (7-52) months, 4 patients were observed to be disease-free, 2 patients had pelvic recurrence and 2 patients died.

Conclusion: IORT increases the effectiveness of surgery for local control in recurrent rectal cancer and additionally decreases the risk of toxicity, thus enabling the application of high dose radiotherapy.

Keywords: Recurrent rectal cancer, intraoperative radiation therapy, multimodal treatment 
$\mathbf{R}$ ektum kanseri tedavisinde total mezorektal eksizyon ile cerrahi teknikte sağlanan gelişmelerin yanısıra, neoadjuvan ve adjuvan tedavilerdeki ilerlemeler sayesinde nüks oranı \%4-8 oranına gerilemiştir (1). Hastaların yaşam kalitesini ileri derecede bozan lokal nükste tedavisiz sağkalım ortalama 6-7 aydır (2,3). Nüks rektum kanserinde visseral rektal fasya gibi doğal bariyelerin olmaması hastalığın bu alanda sınırlı kalma ihtimalini azaltır (4). Lokal nüks gelişen rektum kanseri tedavisinde kemoterapi $(\mathrm{KT})$, eksternal radyoterapi $(\mathrm{RT})$ ve cerrahiyi içeren multimodal tedavi uygulanmakla birlikte küratif rezeksiyon yapılan hastalarda bile tekrar nüks gelişme olasılığı çok yüksektir (5). Nüks rektum kanseri tedavisinde uygulanan multimodal tedaviye intraoperatif radyoterapi (IORT) eklendiğinde lokal kontrolde ve sağkalımda anlamIı iyileşme sağlanabildiği bildirilmiştir (6).

IORT radyasyonun cerrahi sırasında rezeksiyon yapılmış tümör yatağına veya komplet rezeksiyon yapılamayan lezyonlarda rezidüel tümör yatağına, cerrahi insizyon kapatılmadan önce bir aplikatör yardımı ile tek fraksiyonda yüksek doz (8-21 Gy) radyoterapi verilmesidir (7). IORT meme, yumuşak doku tümörleri, jinekolojik tümörler, baş-boyun, pankreas ve kolorektal tümörlerin tedavisinde lokal kontrolü artırmak için primer veya boost tedavisi olarak kullanılmaktadır (8). Preoperatif kemoradyoterapi (KTRT) sonrası lokal nüks gelişen rektum kanseri hastalarında IORT kullanımı normal dokulara radyasyon maruziyetini minimuma indirdiği için etkin bir tedavi modalitesi olarak karşımıza çıkmıştır (9). Özellikle reirradyasyon uygulanacak hastalarda küçük bir alana yüksek doz verilmesini sağladığı için eksternal radyoterapiden daha güvenli ve etkin bir yöntemdir. IORT megavoltaj elektron ışınları, ortavoltaj X ışınları ve HDR brakiterapi yöntemleri kullanılarak yapılabilmektedir. IORT az sayıda merkezde olduğu için ülkemizde bu konudaki deneyimler çok sınırlıdır. Bu çalışmada lokal nüks rektum kanseri nedeniyle radikal cerrahi ile birlikte IORT uyguladığımız hastaların sonuçlarını sunmayı amaçladık.

\section{Materyal-method}

Kasım 2012-Aralık 2016 tarihleri arasında Acıbadem Mehmet Ali Aydınlar Üniversitesi Tıp Fakültesi, Maslak Hastanesi'nde nüks rektum kanseri nedeniyle radikal cerrahi ve IORT uygulanan hastaların verileri etik kurul onayı alındıktan sonra retrospektif olarak değerlendirildi. Hastaların demografik ve klinik özellikleri, ameliyat öncesi ve sonrası aldıkları tedaviler, ameliyat özellikleri ve ameliyat sonrası takipleri değerlendirildi.

Ameliyat öncesi tüm hastalar klinik ve radyolojik bulgular ile multidisipliner tümör konseyinde genel cerrah, radyasyon onkologu, medikal onkolog ve radyolog tarafından değerlendirildi. Cerrahi rezeksiyonu zor veya nüks olasılığı yüksek vakaların tamamı tüm diagnostik görüntülemeleri ile beraber detaylı olarak tartışıldı. Hem cerrahi teknik hemde IORT tekniği açısından uygun olup olmadığına karar verildi. Cerrahi rezeksiyon tamamlandıktan sonra anastomoz yapılmadan önce IORT uygulanacak alandan karın içi organlar uzaklaştırılarak tümör alanına IORT uygulandı.

\section{Intraoperatif radyoterapi}

Hastanemizde IORT için hazırlanmış bir adet ameliyathane bulunmaktadır. Bu ameliyathane, iyonlaştırıcı radyasyon yayan cihazlar için Türkiye Atom Enerjisi Kurumu tarafından lisanslama yönetmeliğine göre zırhlaması yapılmış olup kurum tarafından lisans alınmıştır. IORT planlanan hastalar için bu ameliyathanede her işlem öncesi bütün enerjiler için gerekli "output (verim)" ölçümleri alınmaktadır. Ameliyat tarihinde cerrahi rezeksiyondan sonra radyoterapi ekibi ameliyathaneye davet edilmiştir. Radyasyon onkoloğu tarafından cerrahi sırasında preoperatif değerlendirilmiş olan hastada operasyon sırasında rezeksiyon tipine, yerleşim yerine ve komşu riskli organlar göz önüne alınarak doz ve enerji tanımlaması yapılmıştır. İntraoperatif hedef hacim tayini radyasyon onkoloğu ve cerrah ile beraberce yapılmıştır. Tüm IORT ışınlamaları Sordina Electron Lineer Akseleratörü (LIAC 12, Sordina IORT Technologies, İtalya) ile yapılmıştır. Bu cihazda $3,4,5,6,7,8$ ve $10 \mathrm{~cm}$ çaplarında ışınlama alan genişliğini belirleyen "kon" adı verilen aplikatörler bulunmakta ve 6,8,10,12 MeV enerjilerinde elektron seçimi yapılabilmektedir.

Uygun aplikatör steril şartlarda tümör yatağına yerleştirilip sabitleme yapıldıktan sonra intraoperatif radyasyon dozu, ve ışın enerjisi seçimleri, tümör yerleşimi, boyutu ve riskli organ komşuluğuna göre radyasyon onkoloğu tarafından belirlenmiştir. Seçilen doz ve enerji seçimleri Tablo 1'de verilmiştir. Işınlanan alan hacmi 40-60 mm çapında ve 20-40 mm kalınlığındadır. Doz hesaplamaları medikal fizikçiler tarafından IORT sırasında tüm uygulama ve setup hazırlandıktan sonra yapılmış ve dokümente edilmiştir. Uygun setup kurulup, cihaz etrafında hareketli hazır koruma (polikarbon ve çelik karışımı) panelleri ile zırhlama yapıldıktan sonra ameliyathane boşaltılıp ışınlama gerçekleştirilmiştir. Bu sırada anestezi altında olan hastanın monitorizasyonu yapılmıştır.

\section{Bulgular}

Çalışmada 8 hasta (4 kadın) mevcuttu. Hastaların ortanca yaş değeri 54.5 (33-67) yıldı. Nüks hastalık nedeniyle başvuran 5 hastaya ameliyat öncesi eş zamanlı 
kemoradyoterapi (KTRT) uygulandı. Bir hastaya preop KT uygulandıktan sonra IORT planlı boost olarak kullanıldı. Bu hastaya cerrahi sonrası eksternal RT ve eşzamanlı KT verildi. İki hastada ise rekürren tümör yerleşimi preop veya postop eksternal RT'ye uygun olmadığı için sadece IORT uygulandı. Hastaların demografik ve klinik özellikleri Tablo 2'de gösterilmiştir.

Dört hastaya sfinkter koruyucu rezeksiyon, 2 hastaya abdominoperineal rezeksiyon, 2 hastaya pelvisten kitle çıkarılması ameliyatı uygulandı. Sfinkter koruyucu rezeksiyon yapılan tüm hastalara koruyucu ostomi yapıldı. Ortanca ameliyat süresi 380 (240-420) dakika idi. Hastanede kalış süresi ortanca değeri 8 (4-10) gündü. Nüks tümör yerleşimi 8 hastanın 4'ünde anastomoz hattında, 2'sinde pelviste, 1 'inde kolonda, 1 'inde rektumda görüldü. 5 hastaya R0, 2 hastaya R1, 1 hastaya ise R2 rezeksiyon yapıldı. Bir hastaya periton tutulumu nedeniyle hipertemik intraperitoneal kemoterapi (HIPEK), 1 hastaya ise karaciğerden metastazektomi yapıldı. Histolojik tümör tipi tüm hastalarda adenokarsinomdu. Ortanca tümör çapı $4(2-7,3) \mathrm{cm}$ idi. Hastaların ikisinde patolojik incelemede bölgesel lenf nodu tutulumu tespit edildi. Preoperatif KTRT uygulanan bir hastanın patolojik inceleme sonrasında tümör dokusu tespit edilmedi.

Ortanca IORT dozu 15 Gy (12-21) idi. Hastaların IORT öncesi ve sonrası takip verileri ve IORT uygulamasının detayları Tablo 1'de gösterilmiştir. Hastaların ortanca takip süresi 35.5 (7-52) ay idi. Ameliyat sonrası erken dönemde 2 hastada yara yeri enfesiyonu gelişti. Takipleri sırasında 1 hasta lokal nüks, 1 hasta ise masif tromboemboli nedeniyle eksitus oldu. Diğer 6 hastanın 4'ü hastalıksız, 2 hasta ise nüks hastalık nedeniyle adjuvan tedavi altında yaşamaktadır. Hastalarımızın hiçbirinde IORT'ye bağlı yan etki gözlenmedi.

\begin{tabular}{|c|c|c|c|c|c|c|c|c|c|c|}
\hline Hasta No & $\begin{array}{c}\text { Preop } \\
\text { sadeceKT }\end{array}$ & $\begin{array}{c}\text { Preop } \\
\text { KTRT (Gy) }\end{array}$ & $\begin{array}{l}\text { iORT } \\
\text { (Gy) }\end{array}$ & $\begin{array}{l}\text { Enerji } \\
(\mathrm{MeV})\end{array}$ & $\begin{array}{c}\text { Kon Büyüklüğü } \\
\text { (cm) }\end{array}$ & Rezeksiyon & $\begin{array}{c}\text { Adjuvan } \\
\text { Tedavi }\end{array}$ & $\begin{array}{l}\text { Sağkalım } \\
\text { (ay) }\end{array}$ & $\begin{array}{l}\text { Lokal } \\
\text { Nüks }\end{array}$ & Takip \\
\hline I & - & 54 & 15 & 12 & 6 & $\mathrm{R} 2$ & KT & 52 & - & Hastalıksız yaşıyor \\
\hline ॥ & - & - & 20 & 10 & 4 & RO & KT & 8 & - & Ex (venöz tromboemboli) \\
\hline III & - & $45 / 57,5^{\star}$ & 15 & 10 & 5 & $\mathrm{R} 1$ & KT & 37 & + & Ex ( nüks hastalık) \\
\hline IV & & 54 & 20 & 12 & 4 & $\mathrm{R} 1$ & KT & 39 & + & Nüks yaşıyor (lokal) \\
\hline V & - & - & 21 & 8 & 5 & Ro & KT & 36 & - & Hastalıksız yaşıyor \\
\hline VI & + & - & 12 & 8 & 5 & RO & $\mathrm{KT}+\mathrm{RT}$ & 35 & - & Hastalıksız yaşıyor \\
\hline VII & - & $50 / 35^{\star \star}$ & 12 & 10 & 6 & Ro & KT & 24 & - & $\begin{array}{c}\text { Nüks yaşıyor } \\
\text { (Akciğer metastazı) }\end{array}$ \\
\hline VIII & - & 50 & 15 & 10 & 5 & Ro & KT & 7 & - & Hastalıksız yaşıyor \\
\hline
\end{tabular}

Tablo 2. Hastaların demografik ve klinik özellikleri

\begin{tabular}{|c|c|c|c|c|c|c|c|c|}
\hline Hasta No & Yaş & Cinsiyet & $\begin{array}{c}V K i \\
\left(\mathrm{~kg} / \mathrm{m}^{2}\right)\end{array}$ & $\begin{array}{l}\text { Ameliyat Süresi } \\
\text { (dakika) }\end{array}$ & $\begin{array}{l}\text { Hastanede Yatış } \\
\text { Süresi (gün) }\end{array}$ & Ameliyat & Stoma Durumu & Komplikasyon \\
\hline I & 54 & $E$ & 31,8 & 400 & 4 & Low Anterior Rezeksiyon & Kolostomi & - \\
\hline ॥ & 55 & $E$ & 32,5 & 320 & 10 & Low Anterior Rezeksiyon & İleostomi & - \\
\hline III & 67 & K & 19,6 & 350 & 7 & Pelvik Kitle Eksizyonu & - & - \\
\hline IV & 59 & $E$ & 24,8 & 240 & 4 & Pelvik Kitle Eksizyonu & - & - \\
\hline V & 33 & K & 23,8 & 400 & 9 & Low Anterior Rezeksiyon & İleostomi & - \\
\hline $\mathrm{VI}$ & 40 & K & 28,3 & 420 & 9 & Low Anterior Rezeksiyon & İleostomi & - \\
\hline VII & 51 & $\mathrm{E}$ & 21 & 420 & 10 & $\begin{array}{l}\text { Abdominoperineal } \\
\text { Rezeksiyon }\end{array}$ & $\begin{array}{l}\text { Kolostomi, } \\
\text { Ürostomi }\end{array}$ & $\begin{array}{l}\text { Yara Yeri } \\
\text { Enfeksiyonu }\end{array}$ \\
\hline VIII & 61 & K & 21,8 & 360 & 5 & Abdominoperineal Rezeksiyon & Kolostomi & $\begin{array}{c}\text { Yara Yeri } \\
\text { Enfeksiyonu }\end{array}$ \\
\hline
\end{tabular}




\section{Tartışma}

Rektum kanseri tedavisinde iyileşmelere rağmen çevresel sınır pozifliği \%1-33, lokal nüks \%3-8 arasında devam etmektedir $(10,11)$. Lokal nüks gelişen hastalarda ise yapılacak cerrahi işlem hem teknik açıdan zordur hemde çevresel sınır pozifliği \%45'lere, 3 yıllık lokal nüks \%43'lere ulaşabilmektedir $(12,13)$. Daha önceden neoadjuvan KTRT alan hastalarda normal toksisitesi nedeniyle ikinci seri RT uygulanması zordur. Ancak uygun olan hastalarda pelvik RT veya IORT ile lokal kontrolü arttırmak mümkündür $(12,14)$. Ancak tüm bunlara karşın lokal nüksün tedavisi halen çok önemli bir sorundur ve tedavi planlaması titizlikle yapılmalıdır.

Nüks rektum kanserinde multimodal tedavi içerisinde IORT uygulamasının sağkalım ve lokal kontrolde daha iyi sonuç verdiği ve preoperatif KT ile birlikte sağkalımı artırdığı gösterilmiştir (15-17). 5 yıllık sağkalımın \%30 olduğu nüks rektum kanserinde IORT kullanımı ile sağkalımda \%15'e ulaşan artış sağlanabilmektedir $(16,18)$.

Rezeksiyon sonrası geride kalan tümör durumu $(R 0, R 1, R 2)$ sağkalım ve nüks için en önemli faktörlerin başında gelmektedir $(5,9)$. Lokal ileri ve nüks kolorektal kanserde mikroskopik ve makroskopik hastalık kontrolü için standart radyoterapi dozunun aşılması gerekmektedir (19-21). Wiig ve ark (22) yapmış olduğu çalışmada Ro rezeksiyonda IORT uygulanan ve uygulanmayan hastalar karşılaştırıldığında sağkalım arasında fark saptanmamasına rağmen lokal kontrolde IORT'in etkili olduğu bildirilmiştir. Lokal ileri ve nüks kolorektal kanser nedeniyle cerrahi+iORT uygulanan hastalarda R0 ve R1 rezeksiyon arasında lokal nükste fark saptanmamıştır (23). R2 rezeksiyonun sonuçların kötü olarak beklenmesine rağmen, eksternal RT'ye IORT eklendiğinde sağkalım ve lokal nüksün bu olgularda iyileştiği gösterilmiştir (14). Bizim serimizde yer alan R2 rezeksiyon sonrası IORT uyguladığımız bir hasta 52 aydır hastalıksız olarak takip edilmektedir. Haddock'un yapmış olduğu derlemede nüks rektum kanserinde IORT uygulandığında; R0 rezeksiyon ile lokal kontrol \%60-80, 5 yıllık sağkalım \%4050; R1 rezeksiyon ile lokal kontrol \%30-60, 5 yıllık sağkalım \%20-30; R2 rezeksiyon ile lokal kontrol \%30-50, 5 yıllık sağkalım \%15-25 olduğu bildirilmiştir (9). Nüks rektum kanserinde cerrahi+iORT ile eksternal RT+IORT+cerrahi tedavi proktokolleri karşılaştııılığında eksternal RT alan hastalarda lokal nüks daha düşük, sağkalımın daha fazla olduğu bildirilmiştir $(12,24)$. Bizim çalışmamızda 6 hastaya IORT ile birlikte ameliyat öncesi ya da sonrası dönemde eksternal RT uygulandı. Bu hastaların 3'ünde nüks gelişmedi.
Periton tutulumu olan lokal ileri rektum kanseri tam kür sağlanma ihtimali az olan hasta grubunu oluşturmaktadır. Bu hastalarda anektodal olarak HIPEK ile birlikte IORT'u birleştiren tedavi modalitesi düşünebilir. Klaver ve ark (25) HIPEK ve IORT'u 5 hastada uygulanmıştır. Ortalama 20,6 (10-34) ay takip süresi olan bu olgu serisinde 4 hasta hastalıksız olarak izlenmiştir. Bizim serimizde bir hastaya periton tutulumu nedeniyle HIPEK uygulandı. Adjuvan kemoterapi alan bu hasta 36 aydır hastalıksız olarak izlenmektedir.

Eksternal RT sırasında ışınlama alanına bağırsak anslarının girmesini önleyemediğimizden toksik sonuçlara neden olabilir. Ayrıca kronik diyare, bağırsak obstruksiyonu, fistül ve cilt ülserasyonu gibi ciddi uzun dönem komplikasyonlarda eksternal RT sonrası görülebilir (26). Bu nedenle tekrar RT yapılırken ince bağırsakların ışınlama alanından uzaklaştırılması önem taşımaktadır. IORT ışınlanacak alandan diğer organları uzaklaştırarak hedef alana yüksek doz RT uygulamamıza olanak sağlamaktadır. Böylece RT'nin bağırsaklara olan yan etkilerini azaltabilir. IORT sonrası cerrahi alan enfeksiyonu gelişebilir (9). Mirnezami ve ark (27) yapmış olduğu 29 çalışmayı içeren sistemik derlemede IORT'un ürolojik ve anastomotik komplikasyonlarda artışa neden olmadığı, yara yeri enfeksiyonunda artışa neden olduğu gösterilmiştir. Klink ve ark (28) yapmış olduğu çalışmada IORT+cerrahi ve sadece cerrahi yapılan hastalar karşılaştırıldığında komplikasyon oranının benzer olduğu bildirilmiştir. IORT'un pelviste kullanımını sınırlayan etken periferik sinir hasarı ile oluşturduğu, güçsüzlük ve duyu kaybı oluşturmaksızın ağıı ile kendini gösteren nöropatidir. Nöropati insidansının IORT'de reçetelendirilen doz ile ilişkili olduğu gösterilmiştir. IORT dozunun 15 Gy 'den yüksek olması nöropati riskini artırmaktadır (22). Bizim çalışmamızdaki hastalarda major komplikasyon gelişmemiştir. Iki hastada yara yeri enfeksiyonu gelişmiştir. Buna hasta sayısının azlığı, akılcı ve uygun ostomi uygulaması etken olabilir.

Çalışmamızda hasta sayısının az olması ve kontrol grubunun olmaması eksiklik gibi görünmesine rağmen temel amacımız bu zorlu ve tedavi yönetimi tam belirlenmemiş hasta grubunda IORT tecrübemizi değerlendirmekti. Doğru klinik değerlendirme ve uygun endikasyon ile IORT nüks rektum kanserinde, rezidu kalan olgularda dahi kabul edilebilir sonuçlar sunabilen multimodal tedavi seçeneklerinden biridir. 


\section{Kaynaklar}

1. Kapiteijn E, Marijnen CAM, Nagtegaal ID, Putter H, Steup WH, Wiggers $\mathrm{T}$, et al. Preoperative radiotherapy combined with total mesorectal excision for resectable rectal cancer. N Engl J Med 2001;345:638-46. [CrossRef]

2. Bakx R, Visser O, Josso J, Meijer S, Slors JFM, van Lanschot JJB. Management of recurrent rectal cancer: a population based study in greater Amsterdam. World J Gastroenterol 2008;14:6018-23. [CrossRef]

3. Wanebo HJ, Koness RJ, Vezeridis MP, Cohen SI, Wrobleski DE. Pelvic resection of recurrent rectal cancer. Ann Surg 1994;220;586-97. [CrossRef]

4. Pacelli F, Tortorelli AP, Rosa F, Bossola M, Sanchez AM, Papa V, et al. Locally recurrent rectal cancer: prognostic factors and long-term outcomes of multimodal therapy. Ann Surg Oncol 2010;17:152-62. [CrossRef]

5. Harris CA, Solomon MJ, Heriot AG, Sagar PM, Tekkis PP, Dixon L, et al. The Outcomes and Patterns of Treatment Failure After Surgery for Locally Recurrent Rectal Cancer. Ann Surg 2016;264:323-9. [CrossRef]

6. Hogan NM, Joyce MR. Surgical management of locally recurrent rectal cancer. Int J Surg Oncol 2012;2012. [CrossRef]

7. Gunderson LL, Willet CG, Calvo FA, Harrison LB, edidors. Intraoperative Irradiation: Techniques and Results, 2nd ed. New York: Humana Press; 2011. Erişim: http://radiationondemand.com/ wp-content/uploads/2018/03/2011-Gunderson-IntraoperativeIrradiation.pdf

8. Willett CG1, Czito BG, Tyler DS. Intraoperative radiation therapy. J Clin Oncol 2007;25:971-7. [CrossRef]

9. Haddock MG. Intraoperative radiation therapy for colon and rectal cancers: a clinical review. Radiat Oncol 2017;12:11. [CrossRef]

10. Sagar PM, Pemberton JH. Surgical management of locally recurrent rectal cancer. Br J Surg 1996;83:293-304. [CrossRef]

11. Nagtegaal ID, Quirke P. What is the role for the circumferential margin in the modern treatment of rectal cancer? J Clin Oncol 2008;26:303-12. [CrossRef]

12. Dresen RC, Gosens MJ, Martijn H, Nieuwenhuijzen GA, Creemers GJ, Daniels-Gooszen AW, et al. Radical Resection After IORT-Containing Multimodality Treatment is the Most Important Determinant for Outcome in Patients Treated for Locally Rectal Cancer. Ann Surg Oncol 2008;115:1937-47. [CrossRef]

13. Alberda WJ, Verhoef C, Schipper ME, Nuyttens JJ, Rothbarth J, de Wilt JHW, Burger JWA. The Importance of a Minimal Tumor-Free Resection Margin in Locally Recurrent Rectal Cancer. Dis Colon Rectum 2015;58:677-85. [CrossRef]

14. Suzuki K, Devine RM, Dozois RR, Gunderson LL, Martenson JA, Weaver AL, et al. Intraoperative Irradiation after Palliative Surgery for Locally Recurrent Rectal Cancer. Cancer 1995;75:939-52. [CrossRef]

15. Hahnioser D, Nelson H, Gunderson H, Hassan I, Haddock MG, O'Connell MJ, et al. Curative potential of multimodality therapy for locally recurrent rectal cancer. Ann Surg 2003;237:502-8. [CrossRef]
16. Lindel K, Willett CG, Shellito PC, Ott MJ, Clark J, Grossbard M, et al. Intraoperative radiation therapy for locally advanced recurrent rectal or rectosigmoid cancer. Radiother Oncol 2001;58:83-7. [CrossRef]

17. Mannaerts GH, Rutten HJ, Martijn $H$, Hanssens PEJ, Wiggers T. Comparison of intraoperative radiation therapy-containing multimodality treatment with historical treatment modalities for locally recurrent rectal cancer. Dis Colon Rectum 2001;44:1749-58. [CrossRef]

18. Mannaerts GH, Martijn H, Crommelin MA, Stultiëns GNM, Dries W, van Driel OJR, Rutten HJT. Intraoperative electron beam radiation therapy for locally recurrent rectal carcinoma. Int J Radiat Oncol Biol Phys 1999;45:297-308. [CrossRef]

19. Allee PE, Tepper JE, Gunderson LL, Munzenrider JE. Postoperative radiation therapy for incompletely resected colorectal carcinoma. Int J Radiat Oncol Biol Phys 1989;17:1171-6. [CrossRef]

20. O'Connell MJ, Childs DS, Moertel CG, Holbrook MA, Schutt AJ, Rubin J, Ritts RE. A Prospective Controlled Evaluation of Combined Pelvic Radiotherapy and Methanol Extraction Residue of BCG (MER) For Locally Unresectable or Recurrent Rectal Carcinoma. Int J Radiat Oncol Biol Phys 1982;8:1115-9. [CrossRef]

21. Schild SE, Martenson JA, Gunderson LL, Dozois RR. Long-term Survival and Patterns of Failure after Postoperative Radiation Therapy for Subtotally Resected Rectal Adenocarcinoma. Int J Radiat Oncol Biol Phys 1989;16:459-63. [CrossRef]

22. Wiig JN, Tveit KM, Poulsen JP, Olsen DR, Giercksky KE. Preoperative irradiation and surgery for recurrent rectal cancer. Will intraoperative radiotherapy (IORT) be of additional benefit? A prospective study. Radiother Oncol 2002;62:207-13. [CrossRef]

23. Hyngstrom JR, Tzeng CW, Beddar S, Das P, Krishnan S, Delclos ME, et al. Intraoperative Radiation Therapy for Locally Advanced Primary and Recurrent Colorectal Cancer:Ten-Year Institutional Experience. J Surg Oncol 2014;109:652-8. [CrossRef]

24. Bussieres E, Gilly FN, Rouanet $P$, Mahé MA, Roussel $A$, Delannes $M$, et al. Recurrences of rectal cancers: results of a multimodal approach with intraoperative radiation therapy. French Group of IORT. Intraoperative Radiation Therapy. Int J Radiat Oncol Biol Phys 1996;34:49-56. [CrossRef]

25. Klaver YL, Lemmens VE, Nienhuijs SW, Nieuwenhuijzen GAP, Rutten HJT, de Hingh IHJT. Intraoperative radiotherapy and cytoreductive surgery with hyperthermic intraperitoneal chemotherapy. Five consecutive case reports of locally advanced rectal cancer with synchronous peritoneal carcinomatosis. Strahlenther Onkol 2013;189:256-60. [CrossRef]

26. Mohiuddin M, Marks G, Marks J. Long-Term Results of Reirradiation for Patients with Recurrent Rectal Carcinoma. Cancer 2002;95:114450. [CrossRef]

27. Mirnezami R, Chang GJ, Das P, Chandrakumaran K, Tekkis P, Darzi A, Mirnezami AH. Intraoperative radiotherapy in colorectal cancer: systematic review and meta-analysis of techniques, long-term outcomes, and complications. Surg Oncol 2013;22:22-35. [CrossRef]

28. Klink CD, Binnebösel M, Holy R, Neumann UP, Junge K. Influence of Intraoperative Radiotherapy (IORT) on Perioperative Outcome after Surgical Resection of Rectal Cancer. World J Surg 2014;38:992-6. [CrossRef] 